\title{
Spared musical abilities in a conductor with global aphasia and ideomotor apraxia
}

\author{
ANNA BASSO,${ }^{*}$ ERMINIO CAPITANI,$\dagger$ \\ From the Centro di Neuropsicologia, Università di Milano, Istituto di Clinica Neurologica, ${ }^{*}$ Clinica \\ Neurologica I, $\dagger$ Milan, Italy
}

SUMMARY A conductor suddenly developed global aphasia and severe ideomotor apraxia as a result of an infarct in the territory of the left middle cerebral artery. Although aphasia and apraxia remained unchanged during the following six years, his musical capacities were largely spared and he was still able to conduct. This case provides some evidence in favour of right hemisphere dominance for music.

Most cases of disturbance of musical function to be found in the literature have had concurrent aphasic disorders. According to Benton,' approximately seven of 10 patients described in the literature as amusic also had some kind of language disturbance. Nevertheless, there is incontrovertible evidence that language and music are sometimes mediated by distinct neurobehavioral systems. ${ }^{2-7}$ It has also been suggested that each hemisphere has its role, with the right dominant in musically naive subjects and the left taking over as the degree of musical sophistication increases (refs 8-9; but for contrasting results see also refs 10-11). Clinicopathological correlations for disturbances of musical function are much less abundant than for the aphasic disorders, and there is only a limited amount of information about the site of lesions associated with amusias. This report presents a case of persistent global aphasia and ideomotor apraxia with spared musical function in an orchestral conductor, a man, therefore, of considerable musical education. The other cases in the literature of left hemisphere lesions that resulted in aphasia with spared musical function ${ }^{35}$ were in musicians less severely impaired in language. This case seems particularly interesting because of the coexisting global aphasia, ideomotor apraxia and preserved good musical function.

\section{Case report}

NS, a right-handed male with 13 years of schooling, was an

Address for reprint requests: Dr Anna Basso, Centro di Neuropsicologia, Istituto di Clinica Neurologica, Via Francesco Sforza, 35-20121 Milano (Italy)

Received 30 May 1984 and in revised form 1 September 1984. Accepted 1 September 1984 orchestral conductor with a degree in violin. He had studied composition under Malipiero and conducting under Guarnieri and Scherchen. For many years he was conductor at the Fenice in Venice and later at La Scala in Milan. Aged 67 years, on November 27, 1977, while on a concert tour in the United States, he suddenly developed slight right hemisparesis, right homonymous hemianopia and global aphasia. He was immediately admitted to hospital where an infarct in the territory of the middle cerebral artery was diagnosed. He was discharged on December 14, 1977 and returned to Italy. The patient was first examined in our Aphasia Unit on April 11, 1980, 29 months after onset. General neurological examination showed a slight right hemiparesis more marked at the upper limb, no hemianaesthesia and complete right homonymous hemianopia. A CT scan performed on May 8 (figs 1 and 2) showed a corticosubcortical area of low density involving the temporo-parieto-occipital left lobes.

Neuropsychological examination Speech was confined to a few ready-made expressions, such as "It's difficult", "I know it", "well", etc., which were well articulated and spoken with normal prosody. Picture naming was nil: the patient could not name any of 20 pictures of common objects. He could manage oral and written comprehension for isolated words ( 80 and $100 \%$, respectively) but failed with five out of ten oral commands and five out of five written commands. His score in the Token Test, adjusted for his educational level, ${ }^{12}$ was $9 / 36$ (normal cut-off score 29/36). Spontaneous writing and writing to dictation were severely affected. The patient could sign his name and copy, but otherwise he refused to write, indicating that he was unable. Repetition and reading aloud were impossible: the patient either refused or, when he tried, produced some vowels or isolated meaningless syllables. Severe apraxia was evident. The patient scored 4/20 in a buccofacial apraxia test, and $42 / 72$ (Normal cut-off $53 / 72 ;{ }^{13}$ ) in an imitation test for ideomotor apraxia: the patient was required to imitate with his left arm and hand 24 gestures executed by the examiner; some were single movements and some were sequences; some gestures were symbolic 

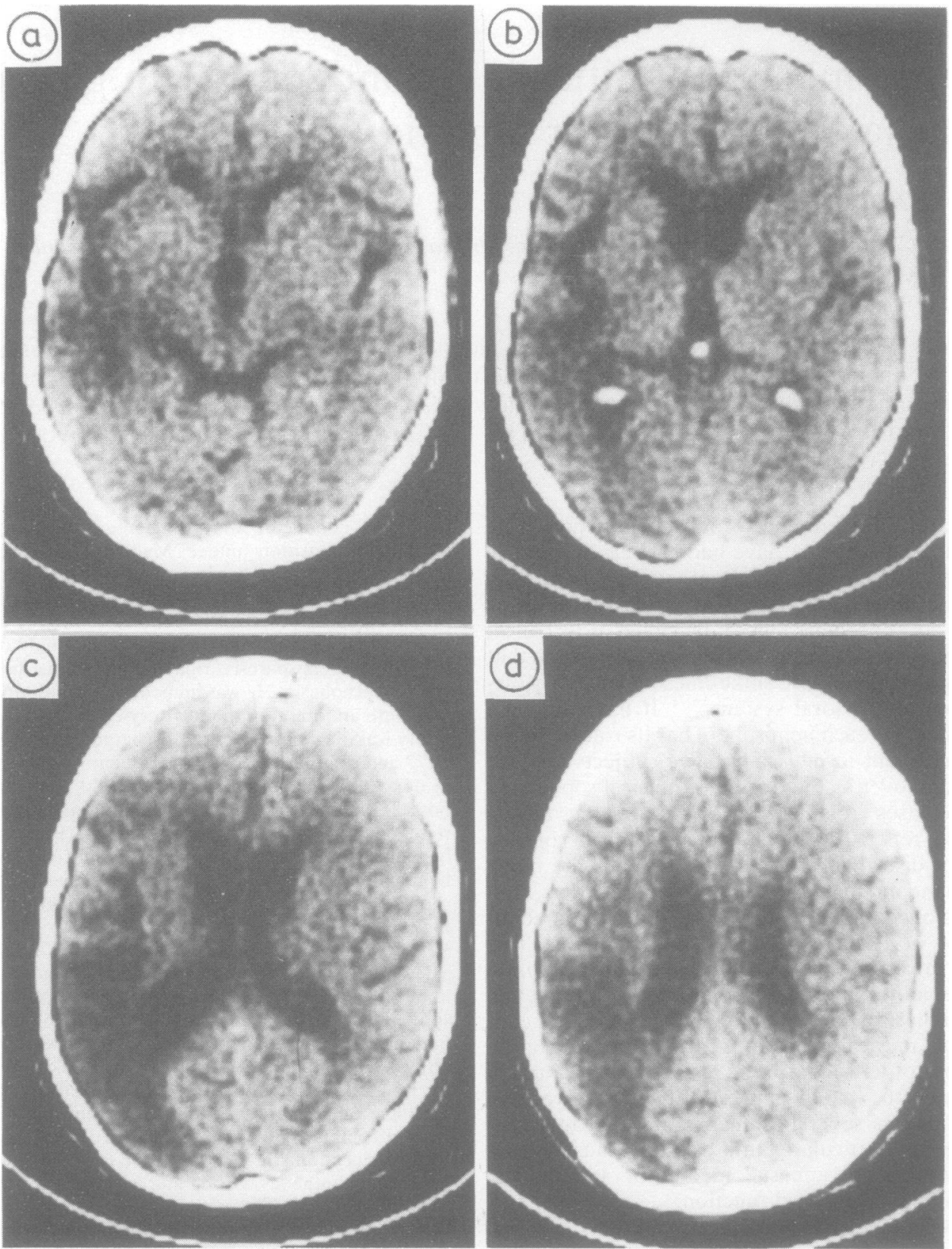

Fig 1 CT scan (8 May 1980) shows a cortico-subcortical low density area involving the temporoparieto-occipital left lobe.

and some were not. Half of the gestures were movements involving the whole arm and hand and half were confined to the fingers. Apraxia of use was also present. When asked verbally and by gestures to use a toothbrush, for example, the patient would move it in front of his eyes, then pass it over his cheeks and neck. There was no constructive apraxia. He was severely acalculic and was able to perform only very simple written sums and no complicated calculations. His acalculia test score was 14/101 (normal cut-off score $\left.74 / 101 ;{ }^{14}\right)$. The patient scored $15 / 36$ on Raven's Coloured Progessive Matrices within a ten minute timelimit. ${ }^{15}$ 


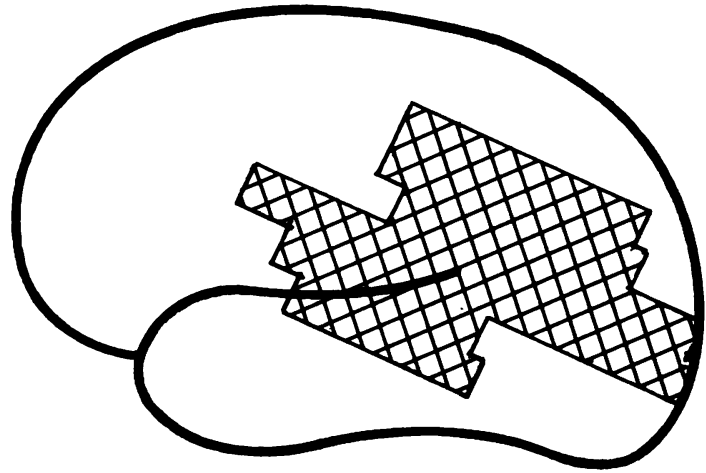

Fig 2 Schematic localisation of the lesion shown in the $C T$ examination of 8 May 1980. The lesion is corticosubortical.

NS underwent language rehabilitation until October 1980 when he was given a second neuropsychological examination. The test results were no different from those of the first examination and it was decided to discontinue rehabilitation. Eight months later, in June 1981, the patient was again seen in the Aphasia Unit and underwent a third examination, again with no change. He still had global aphasia with severe apraxia and acalculia. Rehabilitation was started again but this time using Melodic Intonation Therapy. ${ }^{16}$ In January 1982 the patient was examined for the last time for aphasic disturbances. Speech was nil except for some ready-made sentences that were only slightly more varied than before. Confrontation naming was impossible. He managed comprehension of isolated spoken and written words ( 70 and $100 \%$, respectively) but his Token Test score was $7 / 36$, showing that his auditory comprehension was still severely impaired. Writing to dictation, repetition and reading aloud were all impossible. Buccofacial and ideomotor apraxia, apraxia of use and acalculia were still present. His ideomotor apraxia test score was $20 / 72 .{ }^{13}$ He scored $14 / 36$ on Raven's Coloured Progessive Matrices within a ten minute time limit. During the two years of observation the patient showed no improvement. On April 21, 1983 he had a second cerebrovascular accident, with left hemiparesis. In addition to the old infarct, a CT scan performed May 2 revealed a region of low density in the posterior part of the right temporal lobe, suggesting an ischaemic lesion. NS died on May 4 during an attack of heart failure with pulmonary oedema.

Examination of musical function His musical capacity was tested during the second period of rehabilitation (June 1981 to March 1982). Residual musical abilities were analysed with the help of a professional musician (a piano teacher with experience of orchestral conducting). The examination consisted of five sessions at the patient's home. We also observed some rehearsal sessions and concert performances conducted by NS. A violin was not used in the test because of the patient's right hemiparesis, but even though he had not played the piano since his illness and was astonished to still be able to do so, he collaborated well in the examination with this instrument. However, when he did not feel he could do what the examiner wanted, NS was not keen to collaborate. The observations can be grouped as follows:

(a) activities requiring verbal answers, or musical performances to verbal command; (b) activities requiring neither verbal commands nor verbal answers. (a) Naming of single notes (do, re, etc.) played on the piano by the examiner was generally not possible; when he succeeded it was with delay and uncertainty. The patient had articulation difficulties with bemolle (flat) and diesis (sharp). He was able to sing the C-scale but could not give the names of the notes, uttering "ta-ta ...", not co-ordinated with the modulation of sound. He was unable to indicate verbally whether a given chord was major or minor and could not verbally comprehend the difference between the three types of minor scales (natural, harmonic and melodic), even though he could play them when the examiner gave him a lead. NS was unable to name a G-clef: he could write the clef well enough, though with additional convolutions. Reading aloud the name of single notes was beyond him; he just managed repeated utterances of "do-do ..." although he played them correctly on the piano. Using the full score of Beethoven's 1st Symphony, the patient was requested to name the different musical instruments corresponding to each line. Only after many attempts and the examiner's help could he name them and then with difficulty. When asked to sight-read some music, he reproduced the rhythm fairly well but could not name the notes. Instead of the different names he said "ta, ta ...". This was the picture for several musical pieces for various instruments. His phrasing was very good, with correct pauses and the right bow direction for the violin. To sum up, we can say that whenever a request required language production or comprehension, NS failed. He could correctly reproduce on the piano single notes and short musical phrases played by the examiner but was unable to write them. (b) $\mathrm{He}$ was still able to play the piano with both hands, though the right hand was slightly paretic. When requested to play the major scales, he managed C-major correctly. G-major was a bit fast and rough, but improved with practice and the examiner's insistence on playing slowly. Thereafter he was able to play all the major scales with both hands and improved progressively, notwithstanding the growing number of key-changes. He could play the three types of minor scales correctly, after the examiner. NS was given Hanon's book of exercise for sight-reading and requested to play the first three with their very simple fixed modular ascending series, changing later to a descending series. Execution was correct, and without definite left-right asymmetries. The patient was then given Bartok's Mikrokosmos. These simple exercises are generally used by first and second year students and NS did not know them. He played the first nine exercises correctly after a short preliminary reading. The tenth required three preliminary readings, after which the execution was satisfactory. The more difficult exercises were the same. Execution always improved with practice. NS was unwilling to prepare some more difficult pieces for further testing.

To study his capacity for musical analysis, the examiner played on the piano the intermezzo of the third act of Bizet's Carmen. When it was played too fast on purpose, NS immediately asked for a slower tempo and conducted the whole piece from memory with exact indications for 
the entries of the various instruments. In order to assess further the patient's ability to detect errors of execution the examiner played some pieces from Mussorgski's Pictures at an Exhibition, deliberately inserting errors of rhythm and pitch, though each time less noticeably. The patient never failed to detect them. NS was given the score of Beethoven's Piano Sonata No. 2 to read while the examiner played and he correctly detected minor deliberate errors of execution of a harmonic nature, which thus called for analysis and comprehension of the score.

Conducting We attended rehearsals for a concert performance of two Suites for orchestra and Concertos for one, two, three and four pianos by Bach. The rehearsals followed the normal form: first reading in time, then elucidation of possible inconsistencies between the conductor's and orchestrals' scores, and finally a reading concentrating on agogical and dynamic elements. The communication between NS and the orchestra was limited to gestures. Whenever the performance was halted, NS would show the first violin where they had to start from and he in turn would communicate it to the orchestra. NS was unable to communicate the number corresponding to the measure from which to start by means of gestures (a procedure sometimes adopted by a conductor whose language is different from that of the musicians). The orchestra was not bothered by these procedures and simply attributed the patient's language difficulties to "old age". NS was perfectly able to point out mistakes in execution. In one case, when a cellist started to play at the wrong moment, he immediately stopped him without interrupting the rest of the orchestra and later signalled to the cello to join in at the right moment. NS also tried various instrumental combinations for a concertino, and was able to compare the results and choose the performance he liked the best.

Between February and June 1982, NS conducted a number of orchestral performances, among them Verdi's Nabucco, a difficult piece to conduct because of the size of the orchestra and the number of singers, and Casella's Serenata per archi. The latter piece is extremely difficult, with continuous changes of time and measure values. A critic who was present at the first performance of Nabucco and who did not know about NS' illness, remarked that he had conducted with his habitual ease. Also, from other critics' judgements, it is evident that NS was able to come to grips with all the problems the pieces posed. One critic spoke of "the solemn and exquisitely Symphonic cadenza which NS was able to command from the orchestra" (La Provincia di Cremona, 28 February 81), and another states that "the 71-year-old Venetian conductor has shown that his extraordinary gifts remain untarnished, gifts of exceptional musical sense, of easy gesture perfectly suited to the music of to day, and of warm, communicative humanity" (La Repubblica, 14 June 82).

\section{Discussion}

Comparison of NS' praxic, verbal and musical performances shows striking dissociations.

Throughout the two year observation period NS presented severe ideomotor apraxia and apraxia of use. He was still, however, able to play the piano, even if rather awkwardly, not only some overlearned exercises like scales, but also simple music he was not familiar with (for example Bartok's Mikrokosmos). At the same time he was unable to do simple tasks like touching the table repeatedly with each finger of his left hand in turn. In a test session, he would try in vain to imitate with his left hand the "stop" gesture, but he could perform it perfectly at exactly the right moment in front of the orchestra.

Ideomotor apraxia is certainly more evident in a test situation than in the execution of an overlearned movement, but in NS the dissociation was quite striking. In our patient, in fact, not only was a class of complex overlearned movements spared, but also the ability to programme and appropriately execute movements, some of them fairly symbolic and communicative in nature. Even more surprisingly, this gestural communication was successful from an artistic point of view.

It is our opinion that neither the well known dissociation between automatic and voluntary gesture defects in apraxia nor the distinction between new and overlearned gestures can completely explain our case. Rather, it is argued that our patient was able to programme and execute gestures with a high praxic content when they were the motor expression of musical processing. Therefore, we may hypothesise that a neural and functional structure necessary for executing skilled communicative and continuously? generated gestures was spared per se, yet could nok receive the appropriate visual input for executing our apraxia test laboratory-performance. This cur? tailment can be thought to have been caused by the $\vec{\oplus}$ destruction of some areas necessary for the prepara? of tion of the input itself, or, less probably, by a disconnection between these subparts of the praxic systems. In our patient, gestures spared in the musical context were programmed after a complex procedure that included the visual analysis of musical symbols, probably embedded within additional auditory and kinesthetic feed-back stimuli.

Neural models of a praxic system include sensory association areas that feed the information necessary for generating visuokinesthetic engrams and performing sequences of movements to a centre, possibly parietal, that programs complex acts. In turn, the latter centre is connected with a motor association area that programs single movements. NS' lesion spared some deep left hemisphere structures possibly concerned with movement programming (that is the basal ganglia, ${ }^{17}$ ) and, to a considerable extent, the prerolandic regions of the left hemisphere. Two possiblities may thus be envisaged to account for the spared gestures of the patient: (1) the musical processing of the right hemisphere could reach some left hemisphere centres still operative 
for programming movement sequences, but isolated from other kinds of inputs coming from sensory association cortical areas; alternatively (2) the right hemisphere was able to feed the left motor associative area directly with movement programs which it had elaborated.

In conclusion, NS was nearly perfectly eupraxic when conducting (the only noticeable difference being that he did not use the baton any longer); though not so much so when playing the piano, requiring as it does more co-ordinated and finer movements. Nonetheless, even his residual abilities with piano contrasted considerably with the severe laboratory-assessed disturbances during apraxia examinations. Even more striking was the dissociation between NS' verbal and musical performances. Musical function is a very complex system and not just a sum of components such as rhythm, frequencies, duration, pitch, etc. ${ }^{18}$ Musical language has its own words which combine into phrases organised into larger structures, according to the rules of musical grammar. Because of these analogous features, music has often been considered to be a function of the left hemisphere like language. However, no strict cerebral dominance for musical functions has been proven, and both the left and the right hemisphere or both together, have been considered to be the neurobehavioral substrata for musical capacity.

When we first saw NS, it was 29 months after the onset of his aphasia and this prevents us from advancing any hypothesis about his musical capacity in the early days after onset. Later, he was able to resume his professional activities and, even if he did not give many concerts, the reviews were favourable. His verbal capacity, on the contrary, never recovered and had not changed since January 1978 , when his score in an aphasia examination in Padova (Dr F Denes) was similar to his score in ours, except for verbal output which was more abundant.

We can summarise the comparison of his verbal and musical capacities as follows: musical and verbal writing were affected to similar degrees, but this was not so for reading. Verbal reading was severely affected, while musical reading was very good. Although it has been suggested that musical reading and writing involve "skills commonly believed to be language specific", 19 other cases of verbal alexia without musical alexia have already been described..3520 NS' oral verbal expression was severely affected and did not improve over the six years after-stroke. NS could, however, express himself through music. He gave, for example, an interpretation of Nabucco that was all his own and could not have been ascribed to another conductor by an informed ear.

To conclude, we do not claim that NS' musical capacity was undamaged. His piano playing was certainly less proficient than it had been and his refusal to write music could have been to conceal his inability to do so. Receptive function, however, and conducting appeared to us to be unimpaired. Since NS had a large left hemisphere lesion affecting the temporal and parietal lobes to a considerable extent, it seem very unlikely that his residual receptive abilities reflect only the competence of the left hemisphere spared areas. More probably, his case indicates that his musical competence was mainly in the right hemisphere. Right hemisphere mediation for music has been repeatedly emphasised $d^{21-25}$ and several cases of musicians with aphasia who have been able to continue their work have been reported..$^{326}$ Indeed, our observations appear to mirror the recent findings of McFarland and Fortin. ${ }^{7}$ Their patient had damage to the superior temporal and supramarginal gyri of the right hemisphere. He had lost the ability to reproduce rhythmic patterns and had difficulty in identifying familiar melodies. Ours, on the other hand, was perfectly proficient in these tasks after a similar lesion in the opposite hemisphere. Our findings, however, do no fit in with the statement that musical competence is shifted to the left hemisphere in people with higher musical education. ${ }^{8}$

Even if the conclusions to be drawn from the analysis of our patient are highly suggestive for right hemisphere competence for music, the variability of the data reported in the literature warns against making an unconditional generalisation. Individual differences in musical function are extremely variable and of much greater degree than in language capacity. Moreover, in addition to possible differences among subjects in the substratefunction relationship, outstanding musicians and artists like our patient may well be endowed with (or develop) such individual resources that, in a statistical sense, they become true qualitative exceptions not only to the general population, but also to all people with musical education.

This research was supported by a grant from the Consiglio Nazionale delle Ricerche. Maestro Carlo Villa assisted us with the musical examination of the patient.

\section{References}

' Benton AL. The amusias. In: Critchley M, Henson RA, eds. Music and the Brain. London: Heinemann 1977.

2 Botez MI, Wertheim N. Expressive aphasia and amusia following right frontal lesion in a right-hạnded man. Brain 1959;82: 186-201.

${ }^{3}$ Luria AR, Tsvetkova LS, Futer DS. Aphasia in a composer. J Neurol Sci 1965;2:288-92. 
${ }^{4}$ Smith A. Speech and other functions after left (dominant) hemispherectomy. J Neurol Neurosurg Psychiatry 1966;29:467-71.

${ }^{5}$ Assal G. Aphasie de Wernicke chez un pianiste. Rev Neurol (Paris) 1973; 129:251-5.

- Brust JCM. Music and language. Musical alexia and agraphia. Brain 1980;103:367-92.

${ }^{7}$ McFarland HR, Fortin D. Amusia due to right temporo-parietal infarct. Arch Neurol 1982;39:7257.

${ }^{\star}$ Bever T, Chiarello R. Cerebral dominance in musicians and non-musicians. Science 1974; 185:357-9.

"Shanon B. Laterilization effects in musical decision tasks. Neuropsychologia 1980;18:21-31.

${ }^{10}$ Gordon HW. Hemisphere asymmetries in the perception of musical chords. Cortex 1970;6:387-98.

"Zatorre RJ. Recognition of dichotic melodies by muscians and non-musicians. Neuropsychologia 1979; 17:607-17.

12 De Renzi E, Faglioni P. Normative data and screening power of a shortened version of the Token Test. Cortex 1978; 14:41-9.

${ }^{13}$ De Renzi E, Faglioni P, Sorgato P. Modality - specific and supramodal mechanisms of apraxia. Brain 1982; 105:301-12.

${ }^{14}$ Basso A, Capitani E. Un test standardizzato per la diagnosi di acalculia: descrizione e valori normativi. $A P$ Rivista di applicazioni psicologiche 1979;1:551-68.

${ }^{15}$ Basso A, De Renzi E, Faglioni P, Scotti G, Spinnler H. Neuropsychological evidence for the existence of cerebral areas critical to the performance of intelli- gence tasks. Brain 1973;96:715-28.

${ }^{16}$ Albert ML, Sparks RW. Helm N. Melodic intonation therapy for aphasia. Arch Neurol 1973;29:130-1.

${ }_{17}$ Paillard J. Apraxia and the neuropsychology of motor control. Phil Trans $R$ Soc Lond 1982;B 298:111-34.

${ }^{18}$ Henson RA, Wyke MA. The performance of professional musicians on the Seashore measures of musical talent: an unexpected finding. Cortex 1982;18:153-8.

${ }^{19}$ Henson RA. The language of music. In: Critchley M, Henson RA, eds. Music and the Brain. London: Heinemann 1977

${ }^{20}$ Blau JN, Henson RA. Neurological disorders in performing musicians. In: Critchley $\mathrm{M}$, Henson RA, eds. Music and the Brain. London: Heinemann 1977.

${ }^{21}$ Milner B. Laterality effects in audition. In: Mountcastle VB ed. Interhemispheric Relations and Cerebral Dominance. Baltimore: John Hopkins Press 1962.

${ }^{22}$ Luria AR. Higher cortical functions in man. New York. Basic Books 1966.

${ }^{23}$ Bogen JE. The other side of the brain. II: An appositional mind. Bull LA Neurol Soc 1969;34:135-62.

${ }^{24}$ Bogen JE, Gordon HW. Musical tests for functional lateralization with intercarotid amobarbital. Nature 1971;230:524-5.

${ }^{25}$ Gordon HW, Bogen JE. Hemispheric lateralization of singing after intracarotid sodium amylobarbitone. $J$ Neurol Neurosurg Psychiatry 1974;37:727-38.

${ }^{26}$ Assal G, Buttet J. Agraphie et conservation de l'écrituret musicale chez un professeur de piano bilingue. Revuo Neurol (Paris) 1983;139:569-74. 